\title{
Severe Drug Eruption in Guinea Conakry
}

\author{
Mohamed Cissé1 ${ }^{*}$, Thierno Mamadou Tounkara1, Boh Fanta Diané1, \\ Mohamed Maciré Soumah1, Moussa Keita1, Fodé Bangaly Sako², Fodé Amara Traoré2, \\ Houleymatou Baldé1, Aissata Dabo Camara'1, Alhousseine Doumbouya1, Amara Camara1 \\ ${ }^{1}$ Dermatology STD Donka Hospital, Gamal Abdel Nasser University of Conakry, Conakry, Guinea \\ ${ }^{2}$ Infectious and Tropical Diseases Donka Hospital, Gamal Abdel Nasser University of Conakry, Conakry, Guinea \\ Email: ${ }^{*}$ cissebibi1@gmail.com
}

Received 11 October 2014; revised 13 November 2014; accepted 2 December 2014

Academic editor: Fujiwara Hiroshi, Niigata University School of Medicine, Japan

Copyright (C) 2014 by authors and Scientific Research Publishing Inc.

This work is licensed under the Creative Commons Attribution International License (CC BY). http://creativecommons.org/licenses/by/4.0/

(c) (i) Open Access

\section{Abstract}

Severe drug reactions are defined as mucocutaneous complications secondary to systemic administration of drugs likely to be life threatening. Our work was designed to determine the evolutionary epidemiological and etiological characteristics of severe drug reactions to the Department of Dermatology Venereology, at Donka Teaching Hospital. A prospective descriptive study of all cases of severe drug reactions received at the Department of Dermatology Venereology of the Donka Teaching Hospital was conducted over a period of two years, from June 2009 to May 31, 2011. We identified 22 Stevens-Johnson syndrome, 13 Toxic Epidermal Necrolysis, 1 Stevens-Johnson syndrome Border Toxic Epidermal Necrolysis, 1 Drug Rash with Eosinophilia and Systemic Symptoms and 2 Acute generalized exanthematous pustulosis among 481 hospitalized patients, of whom 50 had consulted for drug reactions, that is to say, a frequence of $\mathbf{1 0 . 4 0 \%}$. The Stevens-Johnson syndrome accounted for $44 \%$, the Stevens-Johnson syndrome Border Toxic Epidermal Necrolysis $2 \%$, Toxic Epidermal Necrolysis 26\%, Drug Rash with Eosinophilia and Systemic Symptoms 2\% and Acute generalized exanthematous pustulosis $4 \%$ of drug reaction. The female sex was predominant ( 28 women vs. 11 men), that is to say $71.59 \%$ vs. 26.21 with a sex ratio of 2.55 . The average age of our patients was 29.72 years; the range of ages 21 - 40 years was the most affected (51.28\%) followed by 0 - 20 years $(33.33 \%)$. The lethality rate was $9.09 \%(2 / 22)$ in the Stevens-Johnson syndrome and 53.85\% (7/13) in the Toxic Epidermal Necrolysis. HIV infection was found in 17.95\% $(7 / 26)$ of our patients and $71.42 \%(5 / 7)$ of the deceased. The drug accountability was established in 79.48\%; the most commonly implicated drugs in the Toxic Epidermal Necrolysis were sulfonamides followed by ARVs (nevirapine) and anti TB (isoniazid); in the SJS sulfonamides followed by salts of quinine and anti TB, the only case of DRESS was due to quinine. No drug was found in $20.52 \%$ (8 cases). HIV infection remains a poor prognostic factor. Our study shows the scarcity of Drug Rash with Eosinophilia and Systemic Symptoms and Acute generalized exanthematous pustulosis in our service.

\footnotetext{
${ }^{*}$ Corresponding author.
}

How to cite this paper: Cissé, M., Tounkara, T.M., Diané, B.F., Soumah, M.M., Keita, M., Sako, F.B., Traoré, F.A., Baldé, H., Camara, A.D., Doumbouya, A. and Camara, A. (2014) Severe Drug Eruption in Guinea Conakry. Journal of Cosmetics, Dermatological Sciences and Applications, 4, 339-343. http://dx.doi.org/10.4236/jcdsa.2014.45045 


\section{Keywords}

\section{Severe Drug Eruption}

\section{Introduction}

Drug reactions are the most common adverse drug events reported to the pharmacovigilance centers in France and in the world: about $20 \%$ of notifications of adverse drug events. They complicate $2 \%-3 \%$ of hospital treatment and motivate $1 \%$ and $5 \%$ of consultations in dermatology hospitalizations [1].

Over $90 \%$ of these drug reactions are benign. Severe life-threatening forms are very rare (1 in 10,000 to $1,000,000$ patients) [2]. They represent $5 \%-10 \%$ of drug reactions. These forms due to their morbidity and mortality justify their hospitalization with an estimated vital risk between $2 \%$ and $5 \%$ in acute generalized exanthematous pustulosis (AGEP), 20\% - 25\% in Toxic Epidermal Necrolysis (TEN) and the Stevens-Johnson syndrome (SJS) and 5\% - 10\% in the Drug Rash with Eosinophilia and Systemic Symptoms (DRESS) [3].

If the setting of REGISCAR in the west allowed to clearly identifying the notifications, in Africa little work has focused on serious drug reactions outside Lyell syndrome and Stevens-Johnson.

In Togo it has been notified eight cases of SJS/TEN in patients hospitalized in the Intensive Care Dermatology and burnt at the University Hospital Center of Lome observed between 1995 and 2003 [4]. In Senegal it has been reported in 17 years 50 cases of drug reaction all due to thiacetazone, including 23 cases of TEN (46\%), 25 cases of SJS (50\%) and two mild cases (4\%) [5]. The aim of this work was to determine the frequency of severe drug reactions in hospitalized patients, describe the sociodemographic characteristics, identify the drug(s) responsable and describe the evolutionary terms of severe drug eruptions.

\section{Material and Methods}

This was a prospective descriptive study conducted over a period of two years from June 1, 2009 to May 31, 2011. It focused on all patients hospitalized in the service of Dermatology Venereology of Donka National Hospital for a severe drug eruption. For the development of this work we used individual patient records and standardized data collection sheets "REGISCAR" which is the office of the European civil severe skin reactions. The aim of the study was to reduce the medical and economic burden of severe skin reactions in public health and improve the safety of drug use. In our work no levy was made because of the weakness of the technical platform.

Were included in this study all patients hospitalized for severe drug eruption diagnosed clinically and were excluded patients followed-up for benign forms of drug eruptions (maculopapular rash of 3 cases, 2 cases of Erythema multiforme major, 2 cases of Drug-induced and 4 unspecified cases of pemphigus) and other dermatological diseases hospitalized in the service during the study period.

\section{Results}

We conducted a prospective study of two years from June 1, 2009 to May 31, 2011 on severe drug reactions recorded in the service of Dermatology Venereology of Donka National Hospital.

Thus, out of a total of 481 hospitalized patients we recorded 50 cases of drug reactions with a frequency of $10.40 \%$. These various cases of drug eruptions were divided into 11 cases of benign drug reactions $(22 \%)$ and 39 cases of severe drug reactions with a frequency of $78 \%$ among which 22 cases (44\%) of SJS, 13 cases of toxic epidermal necrolysis (26\%), 1 case of border syndrome SJS/TEN 1 case of DRESS and 2 cases of AGEP a frequency of $4 \%$.

The average age of our patients was 29.72 years, ranging from 5 years to 84 years. Age bracket of 21 - 40 years is the most affected with a frequency of $51.28 \%$ followed by $0-20$ years $(33.33 \%)$.

A drug origin was formally found in $79.48 \%$ of cases (Table 1). HIV serology was requested and performed in 26 of our patients among which there were 7 cases of HIV seropositivity (17.95\%), 19 cases of seronegativity (48.72\%), in 13 patients and HIV serology was not performed due to the shortage of the reagents during this period. 
Table 1. Distribution of 39 cases of severe drug reactions according to causative drugs.

\begin{tabular}{ccc}
\hline Drugs & Number of Cases & Percentage \\
\hline Allopurinol & 2 & 5.13 \\
Anti-tuberculosis (Isoniazide) & 1 & 2.56 \\
Griseofulvin & 1 & 2.56 \\
ARV (Nevirapine) & 5 & 12.82 \\
Sulfamids (Cotixmoxazol) & 12 & 30.77 \\
Beta-lactams (Penicillin) & 3 & 7.70 \\
Doxycyclin & 1 & 3.85 \\
Salts of quinine & 4 & 10.26 \\
Paracetamol & 2 & 7.69 \\
Non identified & 8 & 20.52 \\
Total & 39 & 100 \\
\hline
\end{tabular}

*Non identified $=$ the drug in question has not been identified.

The majority of our patients 30/39 (76.92\%) have evolved favorably. We recorded nine deaths $(23.08 \%)$. The lethality rate was $9.09 \%(2 / 22)$ in the SJS and $53.85 \%(7 / 13)$ in the TEN. The HIV infection was found $77.77 \%$ (7/9) of the deceased.

\section{Discussion}

Our study focused on patients seen in the Department of Dermatology STD of Donka Teaching Hospital, where the diagnosis of severe drug eruption (SSJ TEN DRESS, Acute generalized exanthematous pustulosis) was formally made by a dermatologist. Although this service the reference center for the management of severe drug reactions in the country, our numbers do not necessarily reflect the frequency of these diseases in Guinea, as patients developing these diseases are not routinely transferred or referred to Dermatology. Moreover, given accessibility problems to care centers, both economic and geographical, some patients may escape hospitals, for some patients with severe disease in Africa are treated outside modern health care structures [5].

With 39 cases diagnosed in two years, our work has confirmed the scarcity of DRESS and AGEP, the high lethality of Lyell. As in our study all the other series show a clear predominance of SJS over the TEN.

The DRESS syndrome can occur in any individual, regardless of age and gender. In children, it is yet probably underestimated because the diagnosis is difficult. Eleven cases of DRESS syndrome have been reported in five years in the United States from 1995 to 2000 [6]. For some authors, age would be a factor favoring the occurrence of side effects and they are very important as age increases [7]. In Tunisia in 2010 a study showed 22 cases of AGEP in a retrospective study from 1992 to 2007 [8].

In our study we found a predominance of females $(71.79 \%$ ) versus $28.21 \%$ of male, with a sex ratio male/ female equal to 2.55. However in Lome (Togo) a predominance of 9 men (60\%) vs. 6 women (40\%) with a sex ratio male/female equal to 1.5 was reported in 1997 [9]. In Senegal a predominance of men over women, be it a ratio of one woman to four men, was reported in 2001 [10].

In practice the application of imputability criteria particularly that of the French pharmacovigilance helped us to standardize etiological research and compare the results of different authors. In our study, as with most other authors [10]-[13], anti-infectious sulfonamides were the most frequently involved drugs. They were followed by the antiretrovirals and quinine. Indeed, the anti-infectious sulfonamides are known as important providers of drug eruptions and their predominance in our study is due to their wide use including for treating opportunistic infections in the HIV infection, malaria, infectious diarrhea and pneumonia. Quinine came in third place unlike European studies where this place is occupied by some non steroid anti-inflamatory drugs (NSAIDs) and analgesics. The frequency of quinine has not been noted by other African writers, despite the high prevalence of malaria in Africa and the frequent use of these molecules. Antiretroviral (nevirapine) occupied the second place 
in our study. Nevirapine is known as a major provider of drug eruptions, and several studies have documented the high incidence of drug reactions induced by nevirapine and their severity [13]-[17]. In opposite, in the series of Pitche et al. in Togo [11] and Mame Thierno et al. in Senegal [5], antiretroviral drugs have not been found, which can be due to the fact that in Togo, despite the high prevalence of HIV infection no HIV-infected patients in this country was on antiretroviral treatment (for economic reasons, the majority of HIV-infected patients did not yet have access to antiretroviral drugs in Africa) [11]. In contrast to our study and those of European authors, several sub-Saharan African authors [5] [10] [16] reported a high incidence of anti TB drugs in the development of SJS/TEN. The frequency of tuberculosis reflects the prevalence of anti TB drugs in these countries such as Guinea. In most of these studies with the exception of Togolese one, these drug reactions were attributable to thiacetazone. In addition, unlike the European and Asian studies [12] [13] [17] [18], drugs against gout, such as allopurinol, were not found in African studies except ours where this molecule was found in 3 cases, probably due to its low use by people in Africa [19]. Furthermore, no infectious cause was found in our patients because of the non-realization of mycoplasma serology, PCR and blood culture.

The lethality rate in the SJS in our series is nearly the same as that reported by most studies.

Indeed, if the SJS has a certain gravity related to the importance of general signs and achievement of the mouth, head discomfort with food and dehydration factor, however it is subject to a low mortality which varies little according to series:

- $9.09 \%$ (2 deaths $/ 22$ cases) in Guinea;

- 7\% (2/27) in Togo [10];

- $0.6 \%(2 / 315)$ in Germany [12];

- 5\% in France [11];

- $5 \%(1 / 22)$ in Malaysia [16].

The major problem remains the sequelae, which are common and can involve the functional prognosis and seriously affect the quality of life. The lethality rate in the TEN observed in our study is higher than that reported in studies of the North, which is usually running around $22 \%$ [19]. Characteristic fact noted in African studies, patients who died during the TEN, both Senegal and Togo as well as in our study were predominantly HIV infected $17.95 \%$ in Guinea, $80 \%$ in Senegal [5] 100\% in Togo. These data, although they are limited by methodological bias, suggest that opportunistic infections induced by immunosuppression due to HIV are a poor prognostic factor in the TEN. A French study has identified seven prognostic factors in the SJS/TEN, originally a severity score, the SCORTEN, which predicts the evolution of TEN [19] [20]. There was not HIV-related immunosuppression among these prognostic factors.

The only case of DRESS found in our study had evolved favorably and without sequelae. It is noted that although the immediate outcome is usually favorable, relapse is common despite the drug eviction and corticosteroids. Evolution is fatal in about $10 \%$ of cases due to fulminant hepatitis, myocarditis or acute renal failure [21].

\section{Conclusion}

This study confirms the predominance of SJS over the TEN among drug reaction and the high lethality of Lyell as well as the scarcity of DRESS and AGEP in our service. Anti-infectious sulfonamides were the most frequently involved drugs, followed by the antiretrovirals and quinine. HIV infection remains a poor prognostic factor.

\section{Conflict of Interest}

None.

\section{References}

[1] Pitche, P., Wolkenstein, P. and Roujeau, J.C. (2001) Toxidermies. Akos encyclopédie pratique de médecine, 2, 9 p.

[2] Collège des enseignants de la Dermatologie en France (2005) Iatrogénie. Diagnostic et prévention: Toxidermies médicamenteuses. Annales de Dermatologie Vénéréologie, 132, 7S160-7S166.

[3] Roujeau, J.C. and Stern, R. (1994) Severe Cutaneous Reactions to Drugs. The New England Journal of Medicine, 338, 1272-1285. http://dx.doi.org/10.1056/NEJM199411103311906

[4] Pitche, P., Mouzou, T., Padonou, C. and Tchangai-Walla, K. (2005) Stevens-Johnson Syndrome and Toxic Epidermal Necrolysis after Intake of Rifampicin-Isoniazid: Report of 8 Cases in HIV-Infected Patients in Togo. Journal of Medicine in the Tropics, 65, 359-362. 
[5] Ndiaye, B., Dieng, M.T. and Camara, C. (1999) Lyell Syndrome in Senegal: Responsibility of Thiacetazone. Médecine d'Afrique Noire, 46, 111-113.

[6] Bosdure, E., Cano, A., Roquelaure, B., Reynaud, R., Boyer, M., Viard, L., et al. (2004) Oxcarbamazepine and DRESS Syndrome: A Pediatric Case of Acute Liver Failure. Archives de Pédiatrie, 11, 1073-1077. http://dx.doi.org/10.1016/j.arcped.2004.05.018

[7] Jeudy, G. and Collet, E. (2008) Clinical Aspects of Severe Skin Allergies. Revue Française d' Allergologie Immunologie Clinique, 48, 115-119.

[8] Mebazaa, A., Kort, R., Zaiem, A., Elleuch, D., Moula, H., Cheikhrouhou, R., Trojjet, S., Mokni, M., Ben Osman, A. and Daghfous, R. (2010) Acute Generalized Exanthematous Pustulosis. Study of 22 Cases. La Tunisie Médicale, 88, 910-915.

[9] Pitche, P., Ategbo, S., Gbadoe, A., Bassuka-Parent, A., Mouzou, B. and Tchangai-Walla, K. (1997) Bullous Toxidermatosis and HIV Infection in Hospital Environment in Lome (Togo). Bulletin de la Société de Pathologie Exotique, 90, 186-188.

[10] Pitché, P., Padonou, C.S., Kombaté, K., Mouzou, T. and Tchangaï-Walla, K. (2005) Stevens-Johnson Syndrome and Toxic Epidermal Necrolysis in Lomé (Togo): Evolutional and Etiological Profiles of 40 Cases. Annales de Dermatologie et de Vénéréologie, 132, 531-534. http://dx.doi.org/10.1016/S0151-9638(05)79333-9

[11] Roujeau, J.C., Guillaume, J.C., Fabre, J.P., Penso, D., Fléchet, M.L. and Girre, J.P. (1990) Toxic Epidermal Necrolysis (Lyell Syndrome) Incidence and Drug Etiology in France, 1981-1985. JAMA Dermatology, 126, 37-42. http://dx.doi.org/10.1001/archderm.1990.01670250043005

[12] Schopf, E., Stuhmer, A., Rzany, B., Victor, N., Zentgraf, R. and Kapp, J.F. (1991) Toxic Epidermal Necrolysis and Stevens-Johnson Syndrome. An Epidemiologic Study from West Germany. JAMA Dermatology, 127, 839-842. http://dx.doi.org/10.1001/archderm.1991.01680050083008

[13] Halvir, D., Cheeseman, S.H., McLaughlin, M., Murphy, R., Erice, A., Spector, S.A., et al. (1995) High-Dose Nevirapine: Safety, Pharmacokinetics and Antiretroviral Effect in Patients with Human Immunodeficiency Virus Infection. Journal of Infectious Diseases, 171, 537-545. http://dx.doi.org/10.1093/infdis/171.3.537

[14] Dukes, C.S., Sugarman, J., Cegielski, J.P., Lallinger, G.J. and Mwakyusa, D.H. (1992) Severe Cutaneous Hypersensitivity Reactions during Treatment of Tuberculosis in Patients with HIV Infection in Tanzania. Tropical and Geographical Medicine, 44, 308-311.

[15] Pitché, P., Drobacheff-Thiebaut, C., Gavignet, B., Mercier, M. and Laurent, R. (2005) Cutaneous Drug-Reactions to Nevirapine: Study of Risk Factors in 101 HIV-Infected Patients. Annales de dermatologie et de vénéréologie, 132, 970-974.

[16] Kamaliah, M.D., Zainal, D., Mokhtar, N. and Nazmi, N. (1998) Erythema Multiforme, Steven-Johnson Syndrome and Toxic Epidermal Necrolysis in North-Eastern Malaysia. International Journal of Dermatology, 37, 520-523. http://dx.doi.org/10.1046/j.1365-4362.1998.00490.x

[17] Yeung, C.K., Ma, S.Y., Hon, C., Peiris, M. and Chan, H.H. (2003) Aetiology in Sixteen Cases of Toxic Epidermal Necrolysis and Stevens-Johnson Syndrome Admitted within Eight Month in Teaching Hospital. Acta Dermato-Venereologica, 83, 179-182. http://dx.doi.org/10.1080/00015550310007166

[18] Mc Gill, P.E. and Oyoo, G.O. (2002) Rheumatic Disorders in Sub-Saharan African. East African Medical Journal, 79, 214-216.

[19] Mockenhaupt, M., Viboud, C., Dunant, A., Naldi, L., Halevy, S., Bouwes-Bavinck, J.N., et al. (2008) Stevens-Johnson Syndrome and Toxic Epidermal Necrolysis: Assessment of Medication Risks with Emphasis on Recently Marketed Drugs. The EuroSCAR-Study. Journal of Investigative Dermatology, 128, 35-44. http://dx.doi.org/10.1038/sj.jid.5701033

[20] Bastuji-Garin, S., Fouchard, N., Bertocchi, M., Roujeau, J.C., Revuz, J. and Wolkenstein, P. (2000) SCORTEN: A Severity of Illness Score for Toxic Epidermal Necrolysis. Journal of Investigative Dermatology, 115, 149-153. http://dx.doi.org/10.1046/j.1523-1747.2000.00061.x

[21] Fortunati, M., Dewulf, V., Jouret, F., Marot, L. and Kanaan, N. (2006) Dress Syndrome or Systemic Hypersensitivity Syndrome to Allopurinol. Louvain Medical, 20, 376-379. 
Scientific Research Publishing (SCIRP) is one of the largest Open Access journal publishers. It is currently publishing more than 200 open access, online, peer-reviewed journals covering a wide range of academic disciplines. SCIRP serves the worldwide academic communities and contributes to the progress and application of science with its publication.

Other selected journals from SCIRP are listed as below. Submit your manuscript to us via either submit@scirp.org or Online Submission Portal.
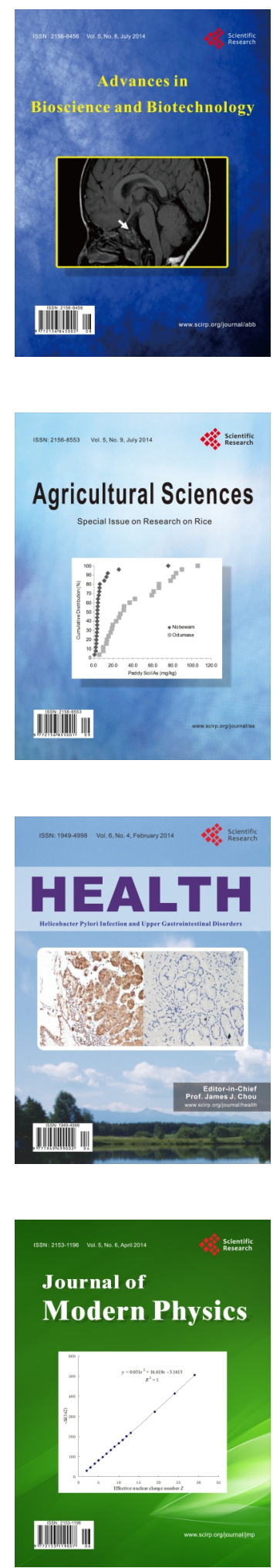
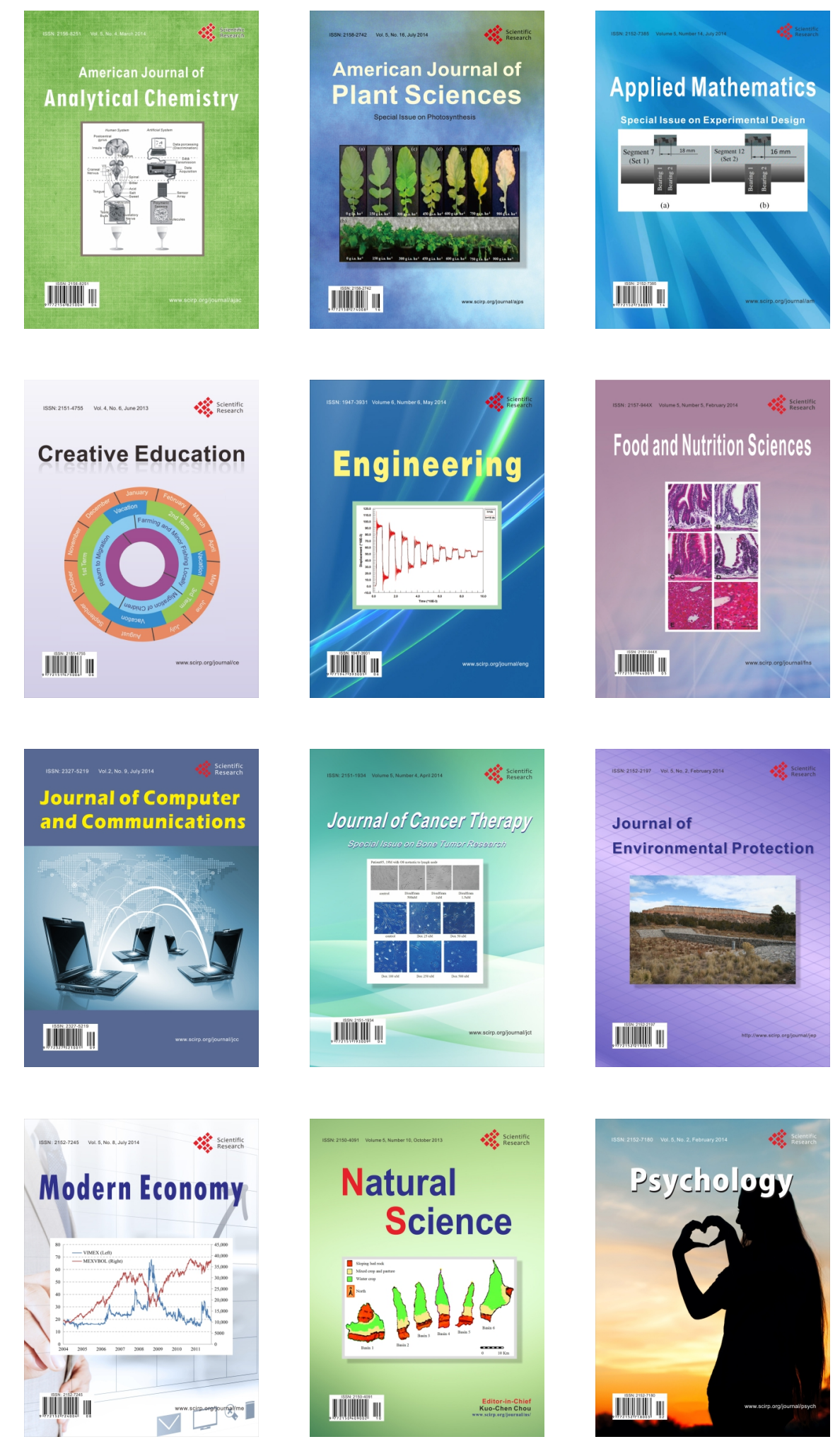